\section{Triple aneuploidy}

SIR,

Webb et al (J Med Genet 1984;21:232) state "This is the first reported case of triple aneuploidy in a male, that is, additional chromosomes $\mathrm{X}, \mathrm{Y}$, and 18 " while publishing their very interesting case report on $49, \mathrm{XXYY},+18$ in a liveborn male.

However, there is a report of triple aneuploidy, that is, additional chromosomes $\mathrm{X}, \mathrm{Y}$, and 8 by Sutherland et al (cited by $\mathrm{me}^{2}$ ) in a mosaic state, $\operatorname{mos} 48, \mathrm{XXYY} / 49, \mathrm{XXYY},+8$, found at paediatric necropsy.

\section{Digamber S Borgaonkar Cytogenetics Laboratory, Wilmington Medical Center, PO Box 2850,} Wilmington, Delaware 19805, USA.

\footnotetext{
References

' Sutherland GR, Carter RF, Bauld R. Smith I, Bain AD. Chromosome studies at the paediatric necropsy. Ann Hum Genet 1978:43:173-81.

2 Borgaonkar DS. Chromosomal variation in man. A catalog of chromosomal variants and anomalies. 3rd ed. New York: Alan R Liss, 1980:558. (A fourth edition, 1984, is now available.)
}

\section{A possible mechanism underlying the sex selectivity of neural tube defect}

SIR,

Dr Seller and Professor Nevin ${ }^{1}$ find that the recurrences of neural tube defect (NTD) in the presence of vitamin supplementation are predominantly in male fetuses. It has been suggested that female anencephalics are more frequently associated with environmental determinants than are male anencephalics. ${ }^{2}$ Seller and Nevin remark that their finding supports the related supposition that the less commonly affected sex would respond less well to environmental therapy. They add "This fact is difficult to explain since the neural tube closes before sex differentiation has occurred".

I should like to offer a form of explanation. I have suggested that the sex of the human zygote is partially controlled by the level of maternal gonadotrophin at the time of conception, high levels being associated with female offspring. ${ }^{34}$ If this is so, it would seem that the mean time of conception and of fetal developmental stages relative to ovulation, and to the whole sequence of maternal endocrinological events following it, is earlier in the case of males than females. In other words, the sequence of maternal events occurs at slightly different developmental stages, on average, for fetuses of the two sexes (at least early in pregnancy). If this is so, then the effect of therapy may be to alter the rate at which one of these sequences occurs so as better to synchronise the mother with the fetus. From conception on, male fetuses-or rather those fetuses which will later turn out to be males-are perhaps better synchronised on average with the sequence of maternal events than are female fetuses, from the point of view of NTD.

Many congenital malformations are sex selective, ${ }^{5}$ and one might wonder whether this is related to the proposed difference between male and female fetuses in regard to developmental timing vis-a-vis maternal timing.

William H James
MRC Mammalian Development Unit,
Wolfson House,
4 Stephenson Way,
London NWI $2 H E$.

References

1 Seller MJ, Nevin NC. Periconceptional vitamin supplementation and the prevention of neural tube defects in south-east England and Northern Ireland. J Med Genet 1984:21:325-30.

2 James WH. The sex ratio in anencephaly. J Med Genet 1979:16:129-33.

3 James WH. Gonadotrophin and the human secondary sex ratio. Br Med J 1980;281:711-2.

+ James WH. Time of fertilisation and sex of infants. Lancet $1980 ; \mathbf{i}: 1124-6$.

5 Arena JFP, Smith DW. Sex liability to single structural defects. Am J Dis Child 1978;132:970-2.

Clinical features of homozygous $\alpha 2$ (I) collagen deficient osteogenesis imperfecta

SIR,

I have read with interest the above article by Nicholls et al (J Med Genet 1984;21:257-62). I would, however, like to take issue on the comments made about the teeth. On page 260 it is stated in the text ". . . relatively normal teeth without dentinogenesis" and the caption for fig 5(e) mentions 
“. . normal pulp cavities exclude dentinogenesis imperfecta".

In the dentine abnormalities that may be associated with osteogenesis imperfecta, the pulp chambers and root canals are either progessively obliterated by the continuous deposition of highly disorganised dentine, or the pulp chambers are larger than normal by a failure of deposition. It is not possible to ascertain whether or not the pulp chambers are in fact enlarged, or to measure the amount of obliteration without taking periapical radiographs and comparing them with age matched controls.

There is also no mention in the article about tooth crown morphology or if, in fact, the teeth are smaller with cusp tips closer together than normal. Nor is there any reference to the presence or absence of short tapering roots.

Although discoloration and opalescence are the more easily observed signs of abnormality, they are not the only criteria for the classification of dentinogenesis imperfecta.

\section{J P GAGE \\ Nuffield Orthopaedic Centre, Headington, Oxford $O X 3 \quad 7 L D$.}

This letter was shown to Dr Nicholls and colleagues, who. reply as follows:

SIR,

We note Mr Gage's comments with interest and fully accept that the diagnosis of dentinogenesis imperfecta can be difficult, especially for nondentists. Undoubtedly the assessment of the finer details of pulp cavity and root canal morphology is the province of dental expertise and well beyond the abilities of the casual observer. Yet most clinicians

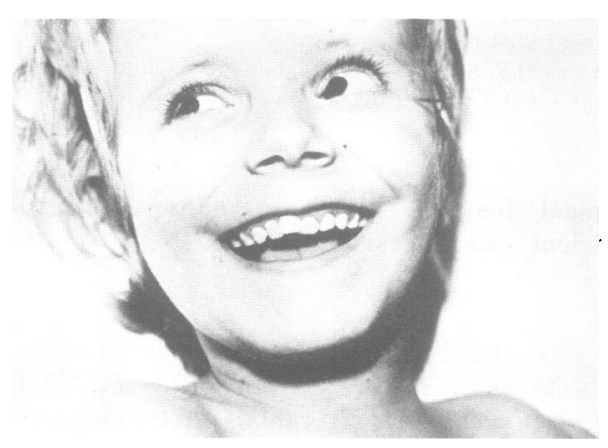

FIG 1 Clinical appearance of patient showing apparently normal teeth morphology and colour.
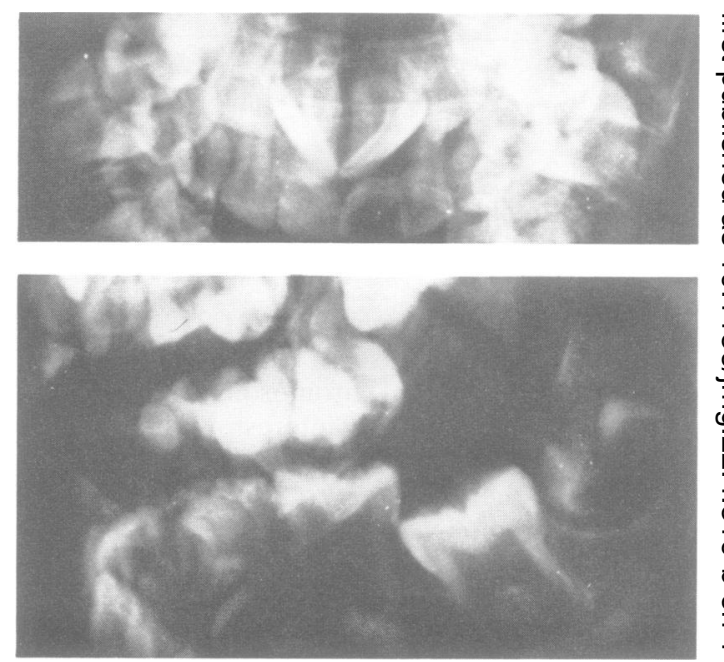

FIG $2 A, P$, and lateral views of patient's dentition enlarged from original skull $x$-ray.

in the field rely upon tooth colour to diagnose dentinogenesis perhaps more than they ought.

Unfortunately panorthotomograms were not available from our patient and we have been unable to obtain a tooth for histological examination (which would settle matters beyond dispute). We therefore showed the clinical morphology of our patient's teeth and their appearance on skull $x$-rays to established dental experts interested in dentinogenesis in the London region. In their opinion neither the clinical appearance (fig 1) nor the tooth radiographs (fig 2) show any evidence of dentinogenesis imperfecta in this patient.

F M Pope ANd A C Nicholls Dermatology Research Group, Clinical Research Centre, Watford Road, Harrow, Middlesex HAI $3 \mathrm{UJ}$.

HLA antigens in South African Afrikaners with heterozygous familial hypercholesterolaemia

Sir,

Familial hypercholesterolaemia $(\mathrm{FH})$ is inherited as an autosomal dominant disorder. The prevalence of FH heterozygotes in the white Afrikaner population of South Africa is 1 in 100 or more and is the highest ever recorded. ${ }^{1}$ We have investigated the distribution of HLA antigens in 82 unrelated 